\title{
On Publishing the 70th Anniversary Special Issue "Progress of the Iron and Steel Technologies in Japan in the Past Decade"
}

\author{
By Shigetoshi ISHIHARA*
}

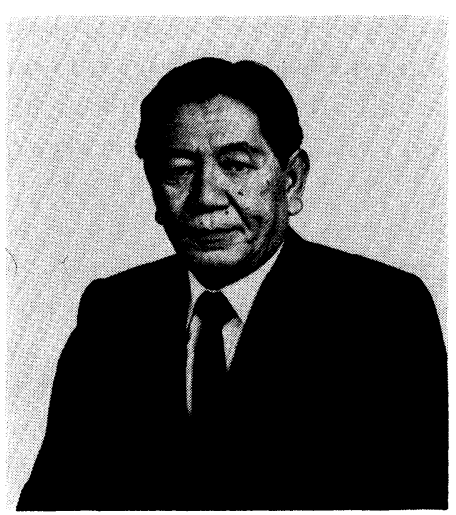

In commemoration of the 70th anniversary of ISIJ in February 1985, we decided to publish a special issue each of Tetsu-to-Hagané and Transactions ISIJ entitled "Progress of Iron and Steel Technologies in Japan in the Past Decade". This special edition will provide an overview of the progress and development of the Japanese iron and steel industry over the last decade.

In 1975 when the 60th anniversary of ISIJ was celebrated, we were in the midst of readjusting our economy so as to overcome the inflation caused by the first Oil Crisis. We still remember how, at that time, the future of the Japanese economy as a whole was too clouded due to the rapidly changing trade conditions to be clearly forecasted. And the same held true for the iron and steel industry in particular. In the course of the next decade, the Japanese economy managed to cope with even the second Oil Crisis and demonstrated considerable strength in overcoming a variety of difficulties. The Japanese iron and steel industry is proud of playing a significant role as one of the key industries that has supported the progress of Japan's economy.

Looking back on our industry over the past ten years, we see that crude steel production dropped to around 100 million tons compared to the previous decade when production showed steady increases and reached a peak of 120 million tons in 1973. As in the case of other basic materials industries, ours also fell into a pattern of low growth.

Major changes also occurred in the demands made by the user industries, as reflected in their shift from a preference for large, heavy products to small, light ones and from an attitude emphasizing consumption to one that stressed energy and resources conservation. These changes were correspondingly reflected in the direction taken by iron and steelmaking technology over the last ten years.

As everyone knows, the two Oil Crises resulted in steep increases in the cost of energy, raw materials and personnel. And this had to be met with strenuous efforts to reduce costs by cutting back on resource consumption, conserving energy, switching to non-petroleum fuels and integrating the various steelmaking processes. Some examples of these efforts are: the exclusive use of coke as fuel in blast furnaces or the change over from crude petroleum injection to powdered coal injection, the reduced use of energy in reheating furnaces due to direct rolling and hot slab charging, improved recycling of waste energy through coke dry quenching and electric generation using blast furnace top pressure, the diffusion of continuous casting aimed at dramatic improvement in the yield rate, and the integration of rolling and other downstream processes.

In the meantime, the users too were experiencing changes in their industries that called for enhanced quality in the properties of steel products. In response to this, the iron and steel makers have put all of their technological know-how into answering the needs of the consumer industries. By industry, the results thus far have been as follows. In the area of energy, high quality oil country tubular goods and new materials for large marine structures such as drilling jackets designed to handle ever deeper oil wells and increasingly hostile drilling environments have been developed. For the automotive industry, high strength steel sheet has resulted along with coated steel sheet to prevent corrosion. The container industry has benefited from the development of thinner materials and weldable TFS, while construction firms have access to corrosion-proof structural steels and the electric machine industry can now make use of highly efficient electromagnetic steel sheet. These improvements have not only sustained the competitiveness of Japanese industry but have contributed greatly to the recovery of the world economy.

Of considerable assistance to the gains made by the steelmaking industry have been the remarkable developments in computer, instrumentation and process technologies. The iron and steel makers have adopted the innovations generated in these areas and have incorporated them in their own enterprises with outstanding results. An early and active participant in the introduction of this know-how, the steel industry has been particularly quick to incorporate the recent and highly developed advances in process technology. 
We believe that this has contributed largely to the improvements registered in product quality and demanded by the steel consumers and to a better yield rate and material consumption ratio. Some representative examples of this are the development and deployment of sensors for blast furnaces, converters, and continuous casters along with the corresponding control systems for stable operation and improved product quality. To this can be added the sensors and accompanying controls over gauge and shape accuracy during hot, cold and temper rolling.

Such advances not withstanding, the trend towards fashionability and light weight products in the consuming industries has produced keen competition between steel and such non-ferrous materials as aluminum, plastic and composite materials. In order to remain competitive, the iron and steel industry has not only striven to enhance the material properties of steel itself, it has also promoted active research and development of composite materials incorporating steel and of new materials like fine ceramics and amorphous metals.

The iron and steel industry of Japan arose from the ashes of World War II to play a major role in leading the Japanese economy through both the era of high economic growth and the following period of economic adjustment imposed by the Oil Crises. During the last four decades, the engineers of this industry, centering around the ISIJ, have consistently rendered a great service. Nevertheless, with the changes that have occurred in the last ten years and the maturing of the Japanese economy, iron and steel have entered into a pattern of slow growth that is threatened even more with the rapid increases in imported materials and the difficulties arising from trade friction with the advanced nations.

In spite of these new obstacles, though, the iron and steel industry of Japan cannot allow itself to slip into decline. Not only must it maintain its current position as the world's foremost steel producer, it must further reinforce that position as it carries on the traditions of its predecessors. This will require innovation and new initiatives in technological development which, in turn, will depend on the resolve of the ISIJ members and their engineers to meet the demands and needs of society at large. In this sense, the next decade will present one of the severest challenges ever to confront the industry's dedicated engineers and research personnel.

Should this special edition succeed in tracing the progress of technology over the last decade and also project the course of technological advances to be made in the coming ten years, my most sanguine hopes will be more than fulfilled.

Finally, I want to take this opportunity to express my sincerest appreciation for the splendid efforts exerted by Dr. Ohmi Miyagawa, chairman of the Special Editorial Committee for Publication of the 70th Anniversary Special Issue, and everyone else who has had a hand in the planning, editing and writing of this issue. 